\title{
THE CONCEPT OF CHANCE IN EARLY CHILDHOOD EDUCATION: AN ANALYSIS FROM THE PERSPECTIVE OF THE REGISTER OF SEMIOTIC REPRESENTATIONS
}

\author{
VERÔNICA YUMI KATAOKA \\ State University of Santa Cruz \\ vykataoka@uesc.br \\ AIDA CARVALHO VITA \\ State University of Santa Cruz \\ aida2009vita@gmail.com \\ CLAUDIA BORIM DA SILVA \\ St. Judas Tadeu University \\ dasilvm@uol.com.br
}

\begin{abstract}
This article aims to investigate the teaching of chance in the context of tactile models (TM) from the perspective of the Theory of Register of Semiotic Representations. In this qualitative research, we sought to identify the different types of semiotic registers and transformations (treatment and conversion), in the solutions of the tasks of the Jefferson's Random Walks Teaching Sequence of children in early childhood education (aged 5 years). We found the presence of different registers, most frequently mother tongue and figurative language, and of conversions. Finally, the TM proved versatile, particularly in addressing the concept of chance, for the mobilization of different semiotic registers and transformations, which can encourage teachers to use this material to work probabilistic concepts in the school context.
\end{abstract}

Keywords: Statistics education research; Tactile model; Concept of chance; Register of semiotic representation; Didactic material; Early childhood education

\section{INTRODUCTION}

In this article, ${ }^{1}$ we aim to investigate the teaching of the concept of chance in the context of tactile models (TM) from the perspective of the Theory of Register of Semiotic Representations (TRSR). The TM is a didactic material composed of pieces and tasks of the Jefferson's Random Walks Teaching Sequence (SE PAJ, Sequências de Ensino Passeios Aleatórios do Jefferson), which enables approaching the concept of chance with equiprobable and non-equiprobable events among other probabilistic concepts ${ }^{2}$ by means of exploration made by the teacher after application.

The term chance is used in this article according to Watson (2006, p. 128) as being “... an approximation of probability, to distinguish more intuitive and experimental aspects of the study of theoretical probability based on sample spaces." Currently, we observe in the media the increasing use of probabilistic terms in various everyday situations, such as the chances of a given team winning a championship, as well as those cited by Batanero (2006): a medical diagnosis, the hiring of insurance, and the evaluation of a student. However, Dias (2004) warned that:

Despite the presence and application of probabilistic concepts in the daily lives of students, ... the informal and intuitive notions that people bring to the classroom about probability are often inconsistent with what we want to teach. It seems that, without formal education, people tend to build certain misconceptions about probability. (p. 145)

\footnotetext{
${ }^{1}$ This article is an excerpt from a study developed under the research project of Kataoka et al. (2018).

${ }^{2}$ Simple and composite events, probability of simple and composite events, deterministic situation, random experiment, expected and observed frequencies, observed and expected patterns.
} 
Lopes (2008) also claimed that intuitions are, sometimes, incorrect, and may lead to the wrong conclusion regarding probability and chance events. We reflect then that the importance of the notion of chance, randomness and other terms related to Probability, is directly related to our way of understanding reality and that approaching this content in school may favor a better understanding and, therefore, assist students in critical reading and interpretation of probabilistic information. According to Gal (2005), this ability to critically read, interpret, transmit, and evaluate probabilistic information is what is called probabilistic literacy.

In Brazil, the recognition of the importance of probabilistic thinking in promoting skills and competencies necessary for the exercise of citizenship led the Brazilian Ministry of Education to incorporate - in the Common National Curricular Base (BNCC, Base Nacional Curricular Comum) (BRASIL, 2017, 2018)-elementary concepts of this content into the component of Mathematics, for elementary and secondary education ${ }^{3}$. For example, in the 1st grade (6-year-old students), teachers should enable students to "classify events involving chance, such as 'it will certainly happen,' 'it may happen,' and 'it is impossible to happen,' in everyday situations" (BRASIL, 2017, p. 81); in the 2nd grade (7-year-old students), "Analysis of the idea of random in everyday situations" (p. 284).

The National Curricular Framework for Early Childhood Education 4 (BRASIL, 1998) indicated that children in this school phase can develop abstract reasoning by manipulating concrete objects, thus indirectly recommending that probabilistic concepts should be addressed. Accordingly, we found the studies of Way (2003), Tatsis et al. (2008), HodnikČadež and Škrbec (2011), and Vita et al. (2016), which lead us to infer that it is possible to address these concepts also with children from early childhood education.

In Way's study (2003), 74 children (4 to 12 years of age) from three public schools in Australia, with no systematic knowledge of probability, were evaluated by tasks in the form of interviews, with games involving random numerical, and spatial generators. During the tasks, the author evaluated whether the strategies given by the children concerned the development of proportional reasoning and the development of the understanding of randomness. The analysis revealed the existence of three stages of probabilistic development: non-probabilistic reasoning, emerging probabilistic reasoning, and probability quantification. In the group whose age range was 4 to 8 years, the researcher observed that the children had a partial understanding of the concept of randomness, not realizing that, even if the event is less likely, it can still occur. When trying to solve tasks that required decision-making, choosing a strategy or even inventing new strategies, there was evidence that children were influenced by previous results, and that equiprobability was not recognized. This research showed us that it is possible to approach intuitive concepts of probability with children through tasks that permeate their daily lives, besides using concrete material, as is our case.

Tatsis et al.'s research (2008) analyzed the language used by 19 five-year-old children from early childhood education and their teacher while they discussed the equity of two games involving the concept of chance. The research investigated the ways in which children verbally expressed their reasoning and, in particular, the strategies they used to justify their views, when trying to understand the notion of equity and the teacher's strategies in establishing this notion. The tasks were designed to examine the children's informal knowledge about probability, being divided into two categories: the prediction of a more/less likely event in a random experiment, and the comparison of probabilities. The results showed that the emergence of verbal arguments revealed the ability of children in early childhood education to be significantly involved in activities related to the notion of justice in a probabilistic game. We believe that this research contributed to our research, as its main focus is on children's intuitive ideas regarding probability that come close to our view of the concept of chance; the authors also analyzed the children's and teachers' discourse regarding the resolution of two tasks using concrete material (roulette game), which was similar to our analysis.

The study by HodnikČadež and Škrbec (2011) aimed to establish the age at which students are able to differentiate between determined, possible, and impossible events and predict their probability. For

\footnotetext{
${ }^{3}$ In Brazil, elementary education constitutes one of the stages of basic education, lasts nine years, and is most often targeted at people aged between 6 and 14 years, while secondary education lasts three years, for people aged between 15 and 17 years of age.

${ }^{4}$ In Brazil, early childhood education is the first stage of basic education, and serves children aged from zero to three years in daycare and four and five years in preschool.
} 
4-5 year olds in preschool, a knowledge test, comprising six probability tasks, was applied orally, as students did not fully master language and writing. Their main results evidenced that more than half of those students were able to achieve both objectives; only equipossible events posed greater difficulty for students of each age group. They also found that the students already brought to school some previous probability knowledge acquired in everyday life. Thus, regarding this study, we firmly believe that the students may bring some prior knowledge of probability from their daily life, which seems to have helped them predict the chances of the events in the tasks.

The study by Vita et al. (2016), conducted with 5-year-old children, aimed at investigating the use of the tactile model for teaching the concept of chance according to Vergnaud's Theory of Conceptual Fields (TCF) and Rabardel's Theory of Instrumentation (TI). Using TCF, the authors' analysis revealed that children throughout the tasks used schemes increasingly appropriate to the situations, mobilizing different operative invariants, thus inferring that appropriation of elements of the conceptual field of chance was ever-increasing. They inferred that the experience in different situations and contexts, has helped the children to develop an intuitive notion of the concept of chance.

In the analysis based on TI, the authors highlighted that the researcher's presence was essential during the tasks, with their strategies of orality, theatricality, creating a ludic atmosphere, encouraging the children to actively participate until the end, presenting their doubts, exposing their beliefs, building their vocabularies, and facilitating their movements. The authors also found that, as the tasks were being applied, the children became increasingly familiar with the model parts. Additionally, they observed that the children proved to be efficient in solving the tasks, considering that they had no formal instruction involving the concept of chance. From this research, we took advantage of the important role the teacher/researcher had in assisting children in the development of tasks, and that diverse situations and contexts can help children to reflect on the concept of chance, providing an increasing appropriation of that concept.

Apart from these studies, which refered to the teaching of probability with children, we also based our research in the considerations made by Cazorla (2006) and Walichinski and Santos Júnior (2013), who emphasized the need to develop and validate accessible teaching materials for the most effective teaching of probability. Coutinho (2001), Batanero and Godino (2002), Lopes (2003), Kataoka et al. (2007), Nishinaka and Yoshikawa (2018), Borovcnik (2018), and Elbehary (2019) recommended that when working on the notion of chance and uncertainty the teacher uses activities that provide students with the conduct of experiments and the observation of events. Nikiforidou (2018) also reinforced the need to introduce children early to activities that give meaning to the notion of possible, impossible, random. According to Nikiforidu and Pange (2010) "every event is characterized by a sort of estimation about is probable, possible, improbable, desirable or unlikely outcome" (p. 305). For Batanero et al. (2016), every citizen needs to build strategies and ways of reasoning that help them make decisions in everyday and professional situations in which the context of chance is present.

Regarding the approach to the concept of chance, Watson (2006) recommended that it be done initially through descriptive activities, moving later to experiments, and a comparison of favorable results with total results. She also advised approaching the concept of chance in relation to decisionmaking in different contexts, including outside the school environment, as well as thinking about this concept associated with situations of justice and equity. Watson presented the ideas and statistical elements that should be addressed in school to understand the concept of chance, such as language, context, questions, bias, justice/equity, proportion, percentage, variation, and randomness.

Considering these authors' guidelines and aiming to develop the students' probabilistic literacy, it is important that teachers address probability concepts from the initial school grades by using contextualized activities that are significant to students experiences or prior learning, and that, therefore, contribute to the transformation into conscious and critical subjects, capable of making decisions and exercising their citizenship.

From this perspective, Vita et al. (2012) developed tactile models (TM) to work-with blind and non-blind students of basic education - on fundaemntal concepts of probability; and from 2012 to date, several studies, such as Vita et al. (2016) and Kataoka et al. (2017), were developed to determine student development and improvement. In these studies, TMs were applied to students, blind and non-blind, from various levels of education (from early childhood education to graduate education at doctoral level) and analyzed considering theories such as: Instrumentation Theory of Rabardel (1995), Conceptual Fields Theory of Vergnaud (1983), and the Principles of Universal Learning Design (Rao 
\& Meo, 2016). Despite the positive results of these studies, our motivation in this article consists in studying TMs considering another theory, the Theory of Register of Semiotic Representations (TRSR) proposed by Duval (1995). We based this desire for research on the reflections concerning the assumptions of this theory, especially considering the claim of Duval (2003), that it is necessary that children have the notion of "distinction between an object and its representation ... strategic point for the understanding of mathematics" (p. 268). After presenting these initial ideas, we reflected that the TRSR is of great value given the possibilities of guiding the pedagogical work considering the different representations of mathematical objects. Thus, what types of semiotic representation are explored in teaching the concept of chance to children of early childhood education in the context of tactile models (TM)? Next, we will present some other aspects of the TRSR.

\section{THEORY OF REGISTER OF SEMIOTIC REPRESENTATIONS}

Duval (1995) proposed the Theory of Register of Semiotic Representation (TRSR), concentrating his studies on the learning of Mathematics with regard to cognitive aspects. The name semiotics derives from the Greek word semeion, meaning sign; therefore, semiotics is the science of signs. In this sense, the semiotic function arises through language, drawing and other representations, being the subject's ability to generate mental images of objects or actions and, through them, represent the object or action, and this function allows thought.

In the case of Mathematics, Duval (2003) emphasized the importance of using representations to understand mathematical objects from two assumptions: the first, calculation operations depend on the representation system used; and the second, the wide variety of semiotic representations used in mathematics: numbering systems, geometric figures, algebraic and formal writings, graphic representations and natural language. Duval (1995) explained the notion of register of semiotic representation as follows:

Semiotic systems should enable carrying out three cognitive activities inherent to any representation. First, constitute a trace or set of perceptible traces that are identifiable as a representation of something in a given system. Then transform the representations by the only rules specific to the system, in order to obtain other representations that can constitute a correspondence of knowledge in relation to the initial representations. Finally, convert the representations produced in a system of representations to another system, so that the latter allows clarifying other meanings relating to what is represented. Not all semiotic systems allow these three fundamental cognitive activities .... But natural languages, symbolic languages, graphic representations, geometric figures, etc. allow them. We then talk about register of semiotic representation. (p. 20)

It is understood that the registers of semiotic representations are the result of a production by the use of rule of signs or symbols, which are expressed through utterances in natural language, algebraic formula, figures and graphs inherent to the object. These registers provide individuals with the exteriorization of their mental representations, making them visible through an exchange of information between the participants in this process.

We may then reflect that semiotic representations contribute very significantly to the development of reasoning, analysis, and visualization capabilities. Moreover, according to Duval (2011, p. 72) "registers are cognitively producing systems, or even creators of new representations, and the production of new representations allows discovering new objects." From this perspective, Duval (2003) claims that in the case of mathematical objects, we may have the following types of register: natural language or mother tongue; figurative language (graph, tables, tree of possibilities), and symbolic language (in algebraic or numerical form).

According to Duval (2003), the mastery of the different representations of the same mathematical object considerably increases the students' capacity to solve problems. He also contends that by analyzing students' performances in facing situations that require representation and coordination between different registers, the teacher will be comprehensively and globally evaluating, that is, the evaluation process will not be fragmented to only one type of register.

Also according to Duval (2003), there are two types of transformations of semiotic representations that are totally different: treatments and conversions. Treatment is the transformation of a representation 
in the very register where it is formed, that is, it is an internal transformation to a register. For example, resolving a question involving area in the algebraic symbolic register or performing a calculation staying strictly in the same system of representation of the numbers.

With regard to conversion, Duval (2003) uses this term to denote the transformations of registers of semiotic representation that occur when there is a change of semiotic system of representation in reference to the same mathematical object. For example: algebraic writing and its graphic representation, a description of a problem in natural language, and its conversion into a numeric register. The conversion operation is not as simple as the treatment operation. In order to carry it out, it is necessary to follow certain well-defined methodological procedures and establish relations between elements of the significant units in each register. Taking as an example the following probabilistic situation, we can observe in the image in Figure 1 the answers considering three distinct semiotic representation systems: mother tongue; figurative language (probability tree), and numerical symbolic language in the conversions performed.

In a group of thirty-two tourists, there are 10 Germans, of which six women, and twenty-two Japanese individuals, of which 10 women. Choosing one of them at random, determine the probability of this individual being:

a) a German; b) of being a Japanese; c) of being German and female; d) of being Japanese and female.

\begin{tabular}{|c|c|}
\hline Register & Answer \\
\hline Mother tongue & $\begin{array}{l}\text { a) Ten out of thirty-two; } \\
\text { b) Twenty-two in thirty-two; } \\
\text { c) Six in thirty-two; } \\
\text { d) Ten out of thirty-two }\end{array}$ \\
\hline Figurative language (probability tree) & $\begin{array}{l}\text { in which A represents Germans, J represents the } \\
\text { Japanese, M represents women, and H represents } \\
\text { men. }\end{array}$ \\
\hline Numeric symbolic language & $\begin{array}{l}\text { a) } P(A)=10 / 32 \\
\text { b) } P(J)=22 / 32 \\
\text { c) } P(A \cap M)=6 / 32 \\
\text { d) } P(J \cap M)=10 / 32 \\
\text { in which } A \text { represents Germans, } J \text { represents the } \\
\text { Japanese, and } M \text { represents women. }\end{array}$ \\
\hline
\end{tabular}

Figure 1. Example of answers to a probabilistic situation with different registers of semiotic representation

In the conversions exemplified, we found the following external transformations of the register of representation: from mother tongue to figurative language and to the numerical symbolic register. According to Duval (2003), the conversion activity cannot be considered as a simple coding task and "... from the cognitive point of view, it is the conversion activity that, on the contrary, appears as the fundamental representational transformation activity, that which leads to the mechanisms underlying 
the understanding" (p. 16). Therefore, conversion requires having a global and qualitative apprehension that coding does not allow.

Moreover, according to this author, conceptualization happens when the subject is able to instantly mobilize a register of semiotic representation of the mathematical object, chosen among the many that are presented, in order to favor the resolution of a given problem in the most economical way possible. It is from this perspective that we analyzed the SE PAJ tasks in the context of the TMs. After presenting our theoretical support, the TM will be presented in further details below.

\section{TACTILE MODEL}

The tactile model consists of pieces (board, houses, gifts, EVA tiles, cup holders, hives, and bell) and the Jefferson's Random Walks Teaching Sequence (SE PAJ). The boards are of two sizes, normaly built on the floor with dimensions of $3 \mathrm{~m} \times 3 \mathrm{~m}$ (Figure 2a) and miniature, made of cardboard and EVA, measuring $30 \mathrm{~cm} \times 30 \mathrm{~cm}$ (Figure 2b). We highlight that the board on the floor is subdivided into nine squares, representing the blocks, while in the miniature the nine blocks are in relief. The houses are of two sizes, normal (Figure 2a) and miniature (Figure 2b), each made of cardboard, and when placed (in the case of miniatures fixed with velcro) on the respective boards, these are called neighborhoods.

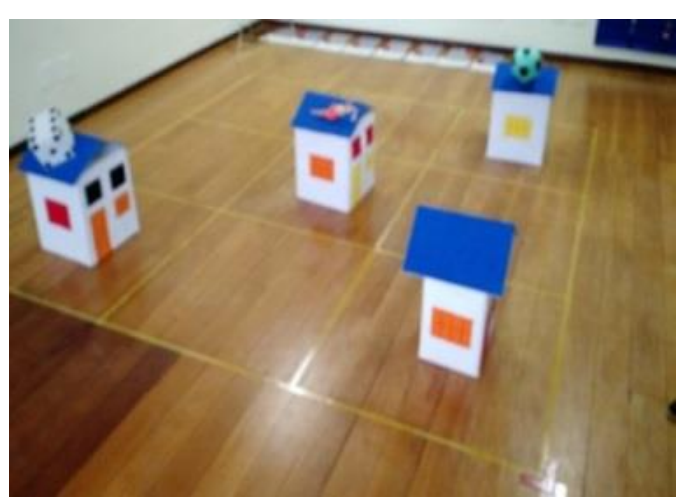

(a)

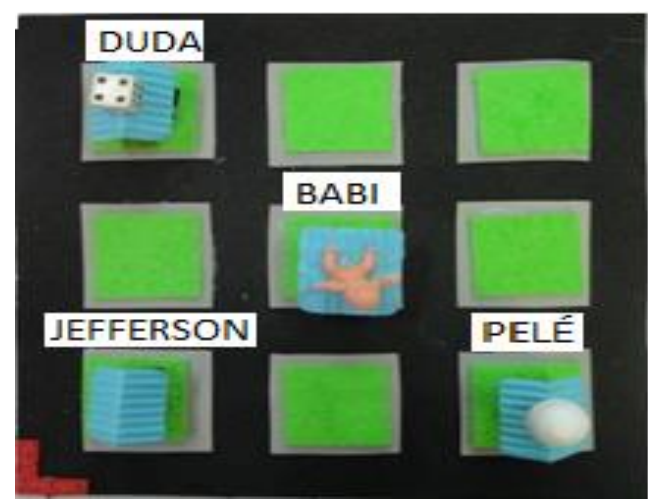

(b)

Figure 2. Three friend boards and normal (a) and miniature (b) houses

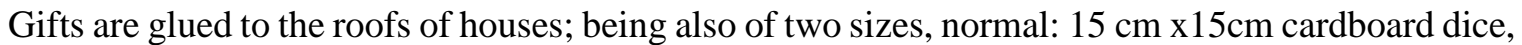
plastic dolls, and balls (Figure 3a); and miniatures: $1 \mathrm{~cm} \times 1 \mathrm{~cm}$ dice, plastic dolls, and foam balls (Figure $3 b)$. The gifts are part of the collection of each of the friends and are given by Jefferson when visiting them, as described in the story of the three friends version SE PAJ ${ }^{5}$ (Figure 4).

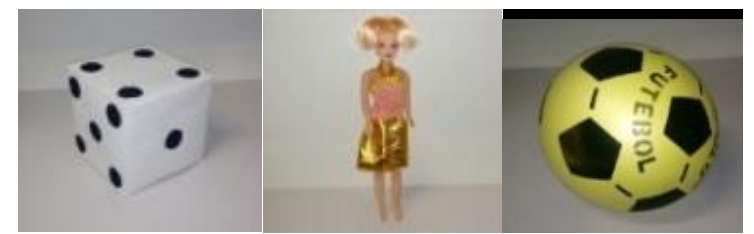

(a)

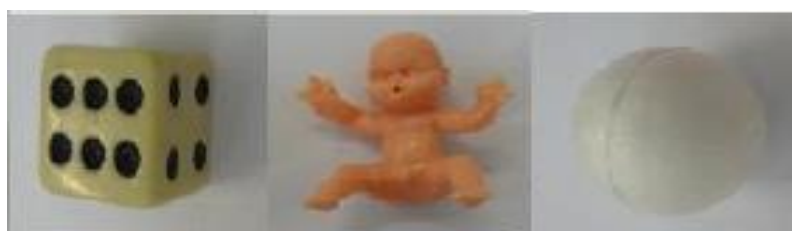

(b)

Figure 3. Normal (a) and miniature (b) gifts

\footnotetext{
${ }^{5}$ There is also the story of the five friends version SE PAJ, with two more new friends for Jefferson to visit: Abel and Beto, who collect, respectively, ring and button. The board on the floor has the dimension enlarged to $5 \mathrm{~m} \mathrm{x}$ $5 \mathrm{~m}$, with 25 blocks, and the miniature board made on the back of the three friends board, also with 25 blocks.
} 
Three friends: JEFFERSON'S RANDOM WALKS

Jefferson and his friends came to live in the same neighborhood. The friends are named: Duda, Babi, and Pelé. Each friend collects a type of object: Duda collects dice, Babi collects dolls, and Pelé collects balls. Jefferson usually visited his friends on the same days of the week in a pre-established order: Monday, Duda; Wednesday, Babi; and Friday, Pelé. However, to make the meetings more exciting, the gang agreed that the visits would be defined by draw, as follows: Jefferson must ring a bell; if a "pim" sound comes out, he will walk a block north, if a "pom" sound comes out, a block east. Each move represents walking a block. The distance from Jefferson's house to each of his friends' houses is always two blocks, so he must ring the bell twice to be able to get to one of his friends' houses and give a gift for their collections.

Figure 4. Story of the 3 friends version SE PAJ

There are EVA tiles in normal size $(6 \mathrm{~cm} \times 6 \mathrm{~cm})$ and also in miniature in $2 \mathrm{~cm} \times 2 \mathrm{~cm}$ size, having quadrangular shape with faces representing Jefferson's movement on the board, namely the textured face if walking north and the smooth face if walking east.

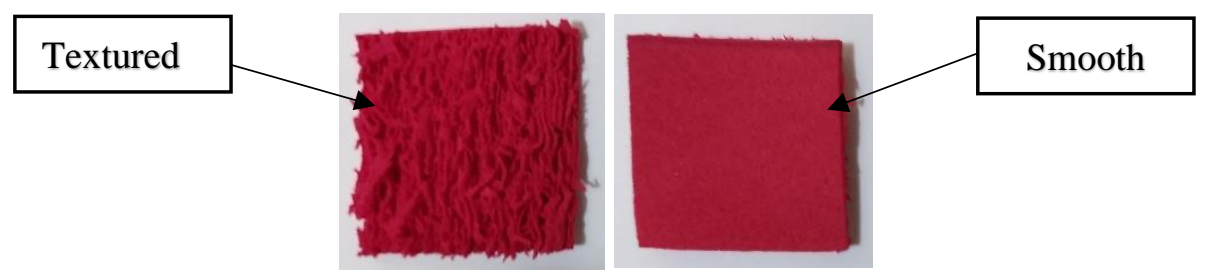

Figure 5. Examples of EVA tiles

The piece called cup holder has the function of organizing, by type, the gifts and the tiles in miniature (Figure 6a). The hives are of two sizes: normal, made of cardboard presenting only 1 row and 6 columns (Figure 6b) and miniature with 9 rows and 6 columns (Figure 6c), which serve to register, with EVA tiles, the paths traversed by Jefferson when visitng his friends (Figure 6c), as well as to build 3 -D pictograms of the events (Figure 6d).

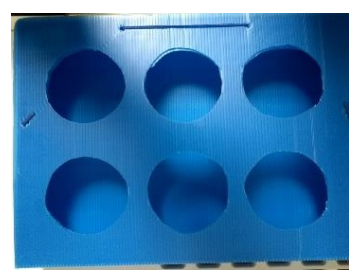

(a)

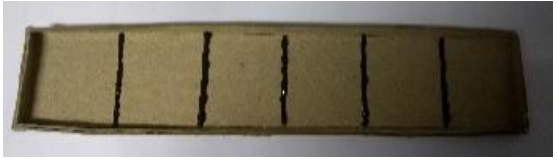

(b)

Figure 6. Cup holder (a), normal hive (b).

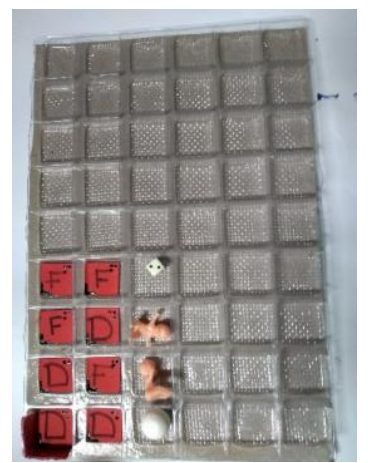

(c)

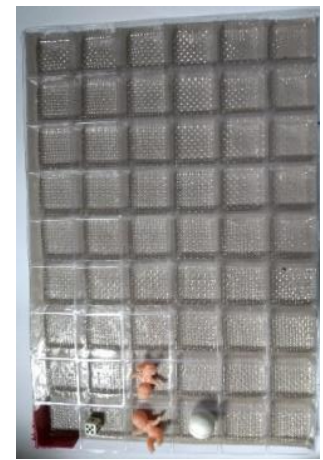

(d)

Figure 6. Miniature hive with paths (c), and with 3-D pictogram (d) 
The bell is a device that has two buttons and two LED lights and its purpose is to perform random draws each time Jefferson reaches a house (Figure 7). When the green light turns on, it produces a "pim" sound, which represents the movement north on the board and red emits a "pom" sound, which indicates the movement east.

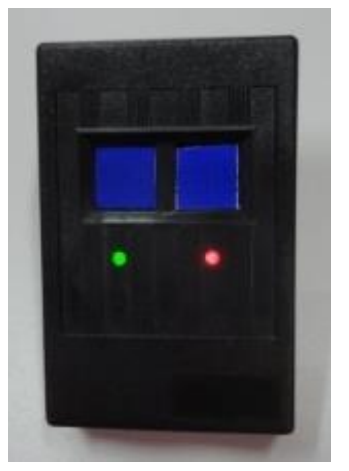

Figure 7. Bell

As for the SE PAJ, it is composed of five tasks, called: ring-a-rosy situation; neighborhood recognition situation; story situation; possible paths situation; and random trial situation. For their conduct, initially the teacher presents a context, so students have to think about the solution considering mainly their daily experiences, then there is promotion of discussion of the registers in oral or written manner, and finally, a conversation group is established, in which answers to other questions are extracted, as well as allowing joint reflection. Next, we will briefly describe, in the image in Figure 8, the first three tasks, highlighting that the fourth and fifth tasks will be presented in the "Results" section.

\begin{tabular}{|c|c|}
\hline Task & Description \\
\hline $1 \mathrm{st}$ & $\begin{array}{l}\text { The concept of chance can be explored with equiprobable and non-equiprobable events. The teacher } \\
\text { starts by explaining that the board on the floor is a new neighborhood, with } 9 \text { blocks, and people can } \\
\text { only move in this neighborhood going forward or right. The teacher says they will move on the board } \\
\text { as a way of playing, using a bell (makes simulations). The teacher divides the students into pairs, } \\
\text { saying that one will ring the bell and the other will move on the board; but that first it is necessary to } \\
\text { determine the order in which the pairs will start the game. To do so, a circle is formed with a } \\
\text { representative from each pair, and they sing the ring-a-rosy song: "UNIDUNITÊ, SALAMÊMINGUÊ, UM } \\
\text { sORVETE COLORÊ, O ESCOLHIDO FOI VOCÊ!", pointing to a student at each syllable, and the student at } \\
\text { which the music stops will be the first to play. She asks the following questions: "Do you think that } \\
\text { this way of choosing who will be the first pair who will start playing on the board is fair? That is, do } \\
\text { you think everyone has equal or different chances of being chosen as first pair, second pair and so } \\
\text { on? Why do you think that?". She finishes the application by drawing the pairs with the numbered } \\
\text { EVA tiles, and discusses with them whether this new way is fair, that is, if everyone has equal or } \\
\text { different chances of being chosen as first, second, etc. }\end{array}$ \\
\hline 2nd & $\begin{array}{l}\text { The concept of chance with equiprobable events can be explored. The teacher begins by explaining } \\
\text { to those who will ring the bell that they must register, in the normal hive, the movement of their } \\
\text { partner on the board using the EVA tiles: the F face represents walking forward and the D face } \\
\text { represents walking to the right. She starts the game, and each pair makes a first move, then the second } \\
\text { movement until all students leave the board. Then she reverses the actions of the students of each } \\
\text { pair and restarts the game. Then she asks the following questions: "Do you think this proposed form } \\
\text { of movement on the board is fair? That is, do you think the student has equal or different chances of } \\
\text { walking FORWARD (pim sound) or RIGHT (pom sound)? Why do you think that?". She concludes, } \\
\text { collectively discussing the answers }\end{array}$ \\
\hline $3 \mathrm{rd}$ & $\begin{array}{l}\text { The concept of chance with non-equiprobable events can be explored. The teacher begins by telling } \\
\text { the story of the } 3 \text { friends SE PAJ, adding the houses, and asking students, with the help of the others, } \\
\text { to move on the board, indicating a way to get to Babi's house. She asks the following questions: } \\
\text { "Without making the draw, we want to know: do you think all friends have equal or different chances } \\
\text { of being visited by Jefferson? Why do you think that?" She collectively discusses the answers. }\end{array}$ \\
\hline
\end{tabular}




\section{METHODOLOGY}

This theoretical research was conducted in a qualitative approach that, according to Bogdan and Biklen (1994), contains five characteristics: the direct source of data is the natural environment, and the researcher is the main instrument; it is descriptive; researchers are more interested in the process than in results or products; researchers analyze the data inductively and, finally, the meaning extracted from the data is of vital importance.

The research subjects ${ }^{6}$ were children of the early childhood education, more specifically from the 2nd grade, aged 5 years, from a private school in the city of Itabuna, Bahia, Brazil. The class consisted of 19 children, but only 14 were present on the day of application, being organized into seven pairs at the discretion of the teacher in charge. In the analyses and presentation of results, we used the notation $D x_{y}$, with $x$ representing the pair $(x=1,2, . ., 7)$ and $y$ representing the child of the pair $(y=1,2)$. For example, we named as $D 1_{1}$ and $D 1_{2}$, referring to children 1 and 2, respectively, of Pair 1 .

We emphasize that by the time of application the children had not received formal education on probability; and that the tasks were verbalized by the researcher and adapted so as not to require written answers, since the children were not able read and write competently. The data were collected in a single two-and-a-half hour meeting by means of video, audio recordings, photographs ${ }^{7}$, in addition to graphic registers made by the children.

In this article, we conduct the analysis from the perspective of the TRSR, only for the fourth and fifth tasks of the SE PAJ, seeking to identify in the children's answers the following registers of semiotic representations: mother tongue (all verbal expression); figurative language (gestures, tree of possibilities, and 3-D pictograms) and numerical symbolic language, in addition to possible transformations: treatment (change within the same register) and conversion (change between registers). We point out that in this article we are considering as figurative representations all gestures made by children using or not the pieces of the model to represent their actions in the construction of the possibility tree and 3-D pictograms.

We support our position about gestures by reflecting on the following definition given by Vygotsky (1988):

The gesture is the visual sign that contains the future writing of the child ... gestures are writing in the air, and the written signs are, often, simple gestures that have been fixed .... The children's own movement, their own gestures, attribute the function of sign to the object and give it signification. All symbolic representative activity is full of these indicative gestures. (pp. 141143)

We thus considered that the case of the children investigated, the gestures to which we refer were used as a form of representation in lieu of the mastery of writing, which they did not yet have. We also emphasize that, according to the BNCC in Early Childhood Education (BRASIL, 2017), among the five fields of experience, we have the field: Body, Gestures and Movements, which recommended that for young children it should be "... proposed an activity with the objective of demonstrating control and adequacy of the use of the body in games, story telling, artistic activities and games" (p. 55). Thus, in the tasks of the SE PAJ, the use of gestures by children was a visual sign that was inherent in their actions in this age group. We also emphasize that the option to evaluate only these two tasks came from the limitation in the number of pages for the composition of the text, thus leading us to restrict our scope of investigation.

\section{RESULTS}

We divided our analysis in light of the TRSR into two subsections. The first corresponding to the results obtained with the children in the fourth task, and the second referring to the fifth task.

\footnotetext{
${ }^{6}$ We point out that the data used in this article were collected under the research project conducted by Vita et al. (2016), since the project of Kataoka et al. (2018) is theoretical only. We chose to use these real data to exemplify, with greater support, the TRSR-based theoretical analysis of the SE PAJ tasks.

${ }^{7}$ We highlight that those responsible for the children signed the Free and Informed Consent Form, thus enabling us to present in the results the photos of the activities without the need to hide the children's faces.
} 


\subsection{ANALYSIS OF THE FOURTH TASK}

In this task the concept of chance with non-equiprobable events can be addressed directly. In the application process, initially, the researcher asked the children to explore the following miniature pieces of the TM: board, houses, hive, EVA tiles and the gifts in the cup holder. At this time, we point out that, even before the researcher asked the children to arrange the houses on the miniature board, most of the pairs had already done so correctly, that is, they matched the miniature board with the board drawn on the floor of the room (Figure 9). Only D2 and D4 required the researcher's help, because they put the houses in exchanged positions, but after establishing a dialogue the doubts were resolved. Thus, in general, we inferred that the recognition and appropriation of the miniature pieces of the TM was occurring in an increasing manner.

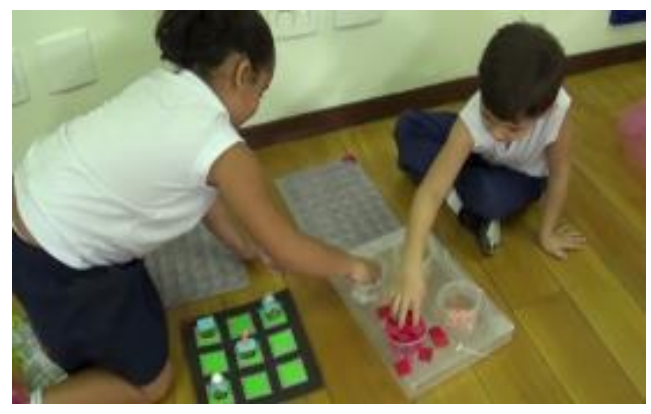

Figure 9. Arrangement of the houses on the miniature board

Continuing, the researcher asked the children to register in the hive all possible ways for Jefferson to reach the home of each of his friends. To that end, she explained that if Jefferson walked east, they should put on a hive row the tile with the smooth side facing up; and if he walked north, with the textured side, and that then they should put in the same row the gift Jefferson gave to his friend. At that time, the researcher performed a simulation, using the hive, of the register of a path to get to Babi's house.

Even with the explanations given, the children were not being able to perform the activity satisfactorily. We inferred that this initial difficulty may have been caused by excess commands (tracing the path on the miniature board, finding the friend and registering with the tiles and the gifts in the hive), or by the distribution of the pieces before explaining their function (they were excited about the material and did not pay attention to what was being said). Based on these assumptions and considering that the different commands can be understood as different registers, we find support to justify this difficulty in the theory itself, when Duval (2003) states that "student failures or blockages at different levels of education increase considerably. Each time a registration change is required or the simultaneous mobilization of two registrations is required" (p. 21).

Continuing, the researcher asked the children to pay attention and explained again, now using the blackboard, but it still required the intervention of the other researchers, who individually assisted the pairs in the execution of the activity (Figure 10).

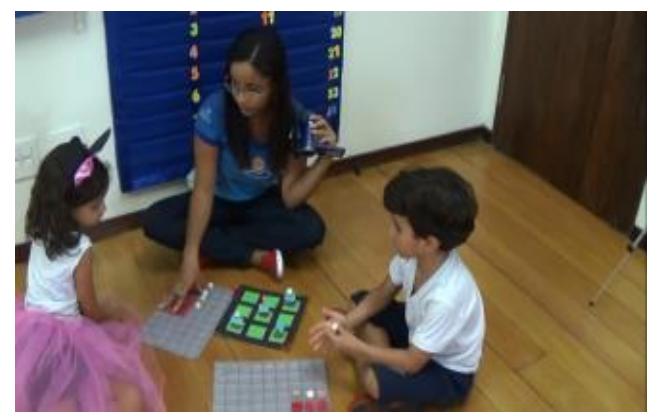

Figure 10. Researcher assisting children in performing the activity 
To illustrate the result of this intervention, we take as an example the following dialogue between the researcher and the pair $D 6$ :

Researcher: ... So, to give the ball to the little friend, Jefferson would have to walk where?

D6 ${ }_{1}$ : He'd have to walk here and then here! (At that time, the child removes Jefferson's house again and simulates the path on the board, performing two movements east and indicating Pelés house.)

Researcher: Very well! So, if he came east, are you going to register in the hive with that smooth part or this other part here?

D6 1 : What?

Researcher: Pay attention! Jefferson walked east. So if he walked east, will you register it with the smooth part or with the "rough" part?

D6 ${ }_{1}$ : $\quad$ To the east ... Smooth!

Researcher: Yes, but here you told me he came east again, so how would this register be like?

D6 ${ }_{1}$ : $\quad$ It would be smooth.

Researcher: Yes, so here you have to put the smooth side of the tile facing up, right? (The child registers it, changing the side of the tile).

Researcher: And now to give the dice, what does he have to do? (The child makes two movements north with Jefferson's little house arriving at Duda's house.)

Researcher: Right! Is this movement north or east?

D6 1 : North.

Researcher: And how would the register be like? (The child makes the register incorrectly.)

Researcher: You said Jefferson walked north and ...?

D6 : $_{1} \quad$ (Flips the tile to the correct side.)

Researcher: Right! What does Jefferson give his little friend now?

D6 ${ }_{1}$ : A dice. (The child puts the gift in the hive.)

By analyzing the dialogue, we observed that the researcher needed a greater number of interventions so the child $D 6_{1}$ could perform the complete registration for Pelé's house than for Duda's house. It seems to indicate that the child was able to gradually establish the relation between the movement on the miniature board, the register tiles, and the gift corresponding to the friend visited. We emphasize that, although the $D 6_{2}$ child did not make any verbal statements, we noticed in the audio recording that the child was attentive and visually monitoring everything that was happening, and sometimes even manipulating the pieces.

Next, we continue presenting the dialogue between the researcher and the pair $D 6$, to determine the other possible path to get to Babi's house:

Researcher: Is there another path that hasn't been registered yet?

$D 6_{1}: \quad$ Yes.

Researcher: Which one? (The child indicates with the finger the other path that leads to Babi's house.)

Researcher: Very well! And how are you going to register this one? You indicated that Jefferson came here (researcher pointing east), so are you going to register it with the smooth or textured side of the tile?

D6 $6_{1}$ : (The child performs the register correctly.)

Researcher: And when Jefferson comes here, do you register it with the smooth or textured side?

$D 6_{1}$ : $\quad$ (The child registers it correctly).

Researcher: Right! And what does Jefferson give his friend while visiting?

$D 6_{1}$ : $\quad$ (The child says nothing, only registers it with a doll.)

Researcher: Are there any other paths that take Jefferson to his friends' houses?

$D 6_{1}$ : No! $\quad$ No,

Researcher: No, right? Very well!

Again $D 6_{2}$ made no verbal statement, and in this part $D 6_{1}$, verbalized little but was already manipulating the pieces. By analyzing from the perspective of the TRSR the two dialogues of the D6 pair with the researcher, we found that these children used in the process of determining the possible paths for Jefferson to reach the home of each of his friends both the mother tongue and the figurative representation, the latter being more frequent. As an example of the use of the mother tongue in the task 
resolution process, we offer the statements: "To the east... Smooth!"; "It would be smooth"; "North", to illustrate the understanding of what was being requested.

In the case of figurative representation, the children used the gestures to make the movement on the board for the determination of the paths to the houses of the three friends, more specifically using Jefferson's house as support to reach Pelé's and Duda's houses ("The child makes two movements north with Jefferson's house arriving at Duda's house") and in Babi's case, using the fingers ("The child indicates with the finger the other path that goes to Babi's house"). In addition, they performed treatments (change in this same register) when they associated the movement on the board with the faces of the EVA tiles and the toys each friend received from Jefferson, registering this information in the hive. Including making corrections when the register was not correct, as in this dialogue excerpt: "Researcher: You said Jefferson walked north and ...? D6 $6_{1}$ : (Flips the tile to the correct side)."

Also, by analyzing these dialogues, we found that conversions also occurred, when $D 6_{1}$ verbalized and at the same time made gestures with the pieces performing the necessary actions, as in the following dialogue excerpts " $D 6_{1}$ : He'd have to walk here and then here! (At that time, the child removes Jefferson's house again and simulates the path on the board, performing two movements east and indicating Pelé's house)" and " $D 6_{1}$ : A dice (puts the gift in the hive)." By evaluating the results of the other pairs, we found that the initial doubts and actions were not different, so we can extend our considerations about the semiotic representations used to all children. Figure 11 shows the hives of the seven pairs representing their trees of possibilities ${ }^{8}$.

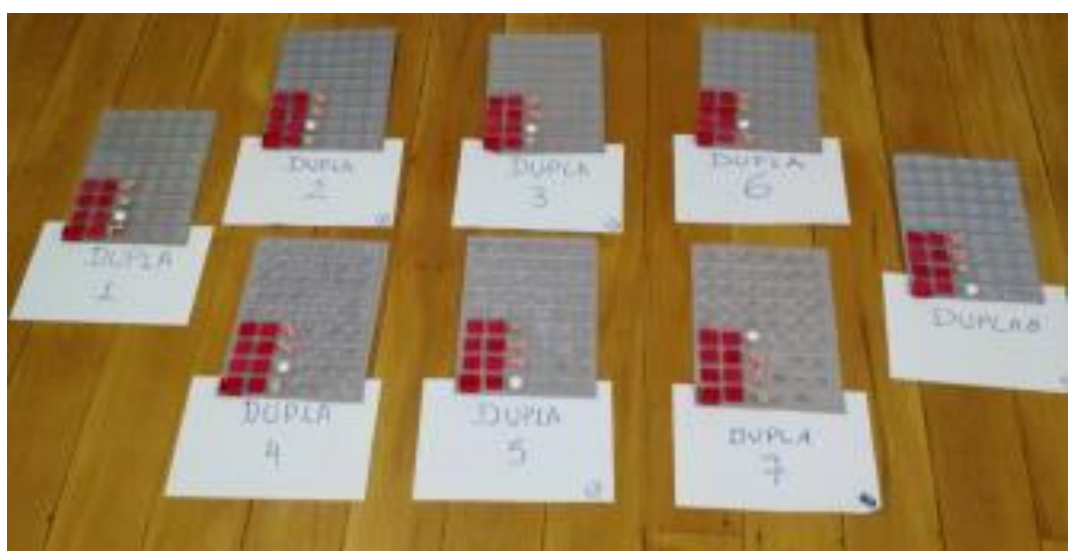

Figure 11. Result of the registers of the possible paths in the hive

Next, the researcher asked some questions collectively of the children about the total paths and the number of times Jefferson visited each friend. As a result, we reported that the children were able to verbalize, observing the hive (verified by audio recording), that there were four paths in total, two of which were to Babi's house, one to Duda's house, and one to Pele's house. By analyzing these results in the light of the TRSR, we observed that the children performed the conversion from figurative representation to mother tongue, since based on the tree of possibilities the children read and verbalized the number of total paths and the number of paths to each friend.

Then, the researcher asked them to arrange the gifts in a clear hive, thus forming a 3-D pictogram (Figure 12), hence using a figurative representation.

\footnotetext{
${ }^{8}$ In this article we use the term "tree of possibilities," although only the last branch of a tree is being represented in the traditional format, because we consider that it ultimately meets the objective of this figurative representation, namely, presenting all possibilities for the occurrence of a given event.
} 


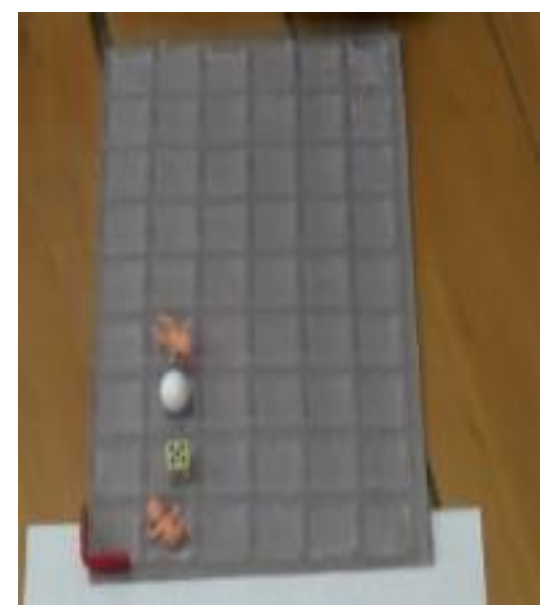

Figure 12. 3-D pictogram of the pair D6

After completing the construction of the pictogram, the researchers asked some questions, addressing each pair separately. As an example of this moment, we present the dialogue between the researcher and D6:

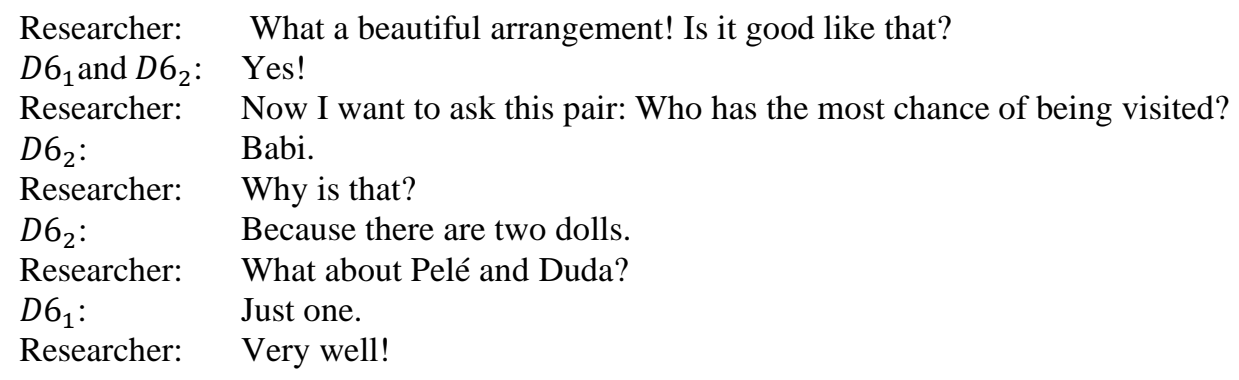

We found that, based on the 3-D pictogram, the D6 pair realized that Babi had a better chance of being visited because it contained two dolls in the hive, that is, associating the term "most chance" with the number of gifts; similar results were obtained in the dialogues with the other pairs. The researcher finished the task, discussing collectively to ratify with the children that Babi had a better chance of being visited and why this result was obtained, as shown in the following dialogue:

Researcher: Who has the most chance of being visited?

All: $\quad$ Babi!

Researcher: Why is that?

$D 5_{1}$ : $\quad$ Because she gets a doll twice.

$D 4_{1}$ : $\quad$ Because she has two dolls collected.

Researcher: Such a beautiful thing! That's right.

We observed in the dialogue that when the children were asked to justify the answer, once again two of them associated the chance of visits to the number of collected objects. Similar results were observed in the research of Tatsis et al.(2008), in which children associated the justice of a game with counting, comparing the sectors of spinners, without it being explicitly requested that they counted or compared the sectors. We also highlight that the manipulation of concrete materials was a factor that helped in understanding the activity, which was also observed in the study of Way (2003) with children of similar age to our study.

We emphasize that the video recording enabled finding that the other children who did not verbalize their justifications were attentive during all questions and were observing their corresponding pictograms. Thus, we infer that they were able to reflect on the chances of each of their friends, and it was understood that Babi had a better chance of being visited by Jefferson than Pelé or Duda, with the same chance. We also highlight that in the studies of HodnikČadež and Škrbec (2011) and Way (2003), 
children in a similar age group to ours, as already commented in the introduction, had higher ease to recognize and predict non-equiprobable events than equiprobable events (explored in the first and second tasks).

Regarding the analysis in the light of the TRSR, we found that the conversion from figurative representation to mother tongue occurred, as the children observed the 3-D pictogram, counting the gifts and relating them to each friend's chances of being visited; that is, comparing the quantities and concluding that Babi had better chances than the other two friends, since they were not equal. We also emphasize that if the children already had mastery of writing, it would be probable that at this point in the task they would also perform a conversion between figurative representation and numerical symbolic representation.

\subsection{ANALYSIS OF THE FIFTH TASK}

The concept of chance with non-equiprobable events can be explored in this task. In the application process, initially, the researcher told the children that they would "play" again on the board on the floor, arousing the interest of all of them, who quickly organized themselves in line, near the board (Figure $13)$.

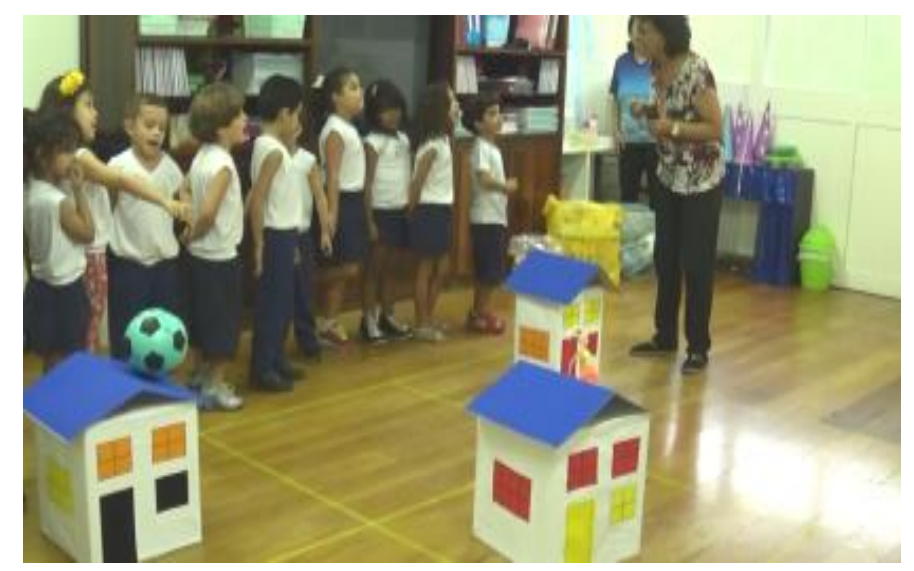

Figure 13. Researcher explaining the fifth situation

The researcher began explaining the task, simulating an experiment, telling the children that if the pom sound played twice it meant they should move twice to the East, and questioned who would be visited and everyone immediately answered "Pelé"! She went on to say that in this case the person should pick up a ball in the bag, which is the gift Pelé receives when visited by Jefferson and put it on the ground at the indicated location. But before starting the experiment, she asked some questions, as shown in the following dialogue:

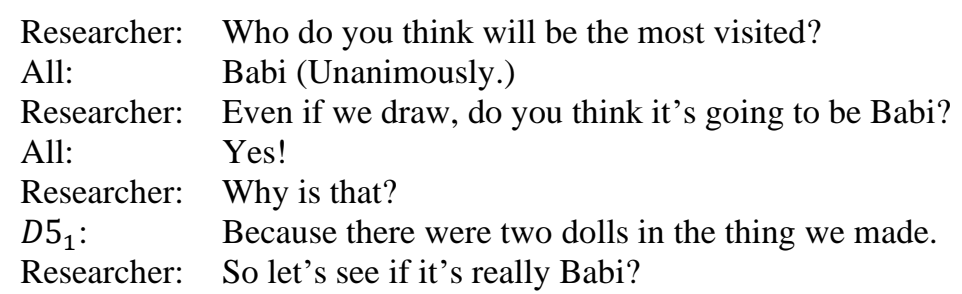

We observed in the dialogue that all children answered that it would be Babi. They were probably influenced by the outcome of the previous situation, as can be exemplified by the statement of $D 5_{1}$. By investigating this answer in the light of the TRSR $D 5_{1}$, we may consider that there was a conversion from figurative representation, the tree of possibilities of the fourth task, to mother tongue.

Continuing the task, each child moved on the board, entering the block where there was a marking and obeying the rules already established, while the others waited for their turn (Figure 14a). Upon 
arriving at their friend's house, the child took the gift collected by them and put it on the floor, thus building a 3-D pictogram (Figure 14b).

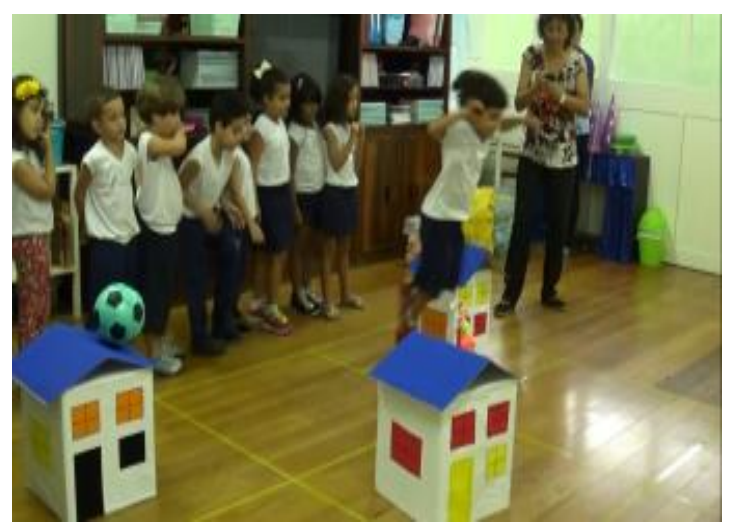

(a)

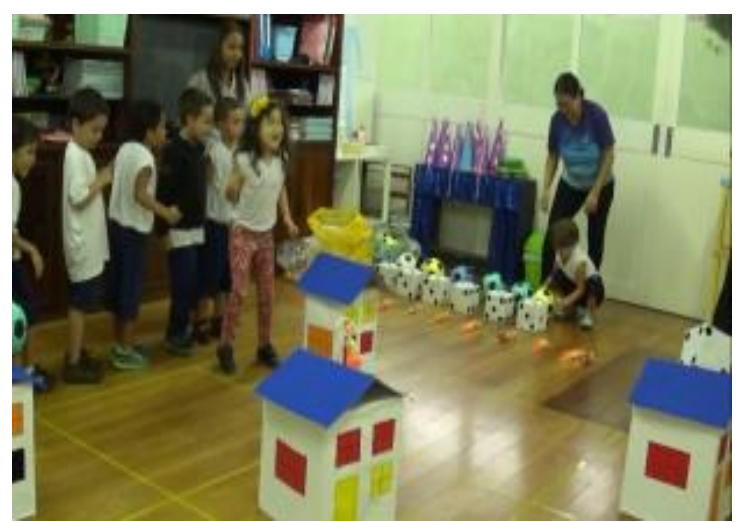

(b)

Figure 14. Child performing the movement (a) and putting the gift in the pictogram (b)

After putting the gift in the pictogram, the child returned to the end of the line and waited for another turn to perform the entire movement again. By means of the audio recording, we found that the pieces of the model and the actions conducted were already familiar to the children-because of the previous tasks - thus they showed no difficulties in making the correspondence between the sound of the bell and the movement on the board, between the visited friend and the toy. Thus, as expected, we found that in this part of the task the students used figurative representation, by means of gestures, more specifically the movements made on the board on the floor to reach the house of each friend. There were also several treatments in this representation, since the children simultaneously coordinated several actions, resulting in the correct correspondence between the visited friend and the gift, and in the construction of the 3-D pictogram with agility and accuracy.

Upon finishing the 29 experiments, the researcher gathered the children around the pictogram to count the gifts, finding that there were 14 dolls meaning 14 visits to Babi, 8 dice that represented visits to Duda, and 7 balls for Pelé (Figure 15).

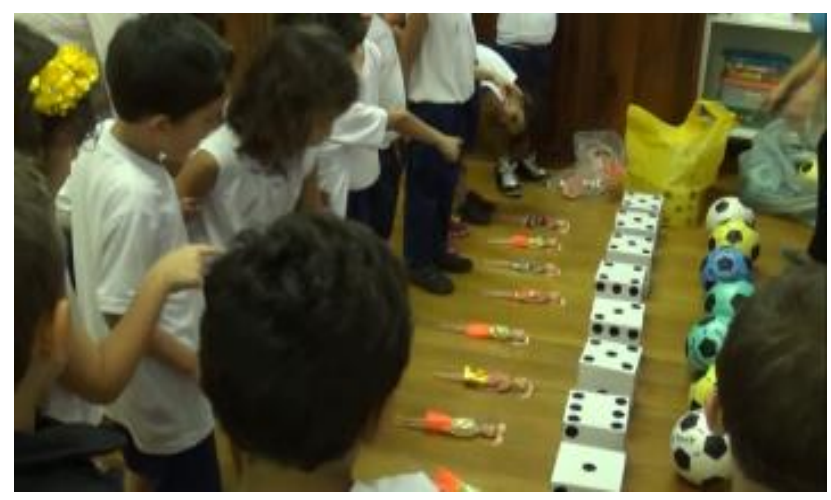

Figure 15. Collective counting of the gifts in the 3-D Pictogram

After counting, the researcher asked the following question: "After the draw, which friend has the better chance of being visited by Jefferson?" At this point, excitement took over the environment when the children found that their opinion had been proven, and they spoke at the same time, "Babi! Babi!" This seemed to indicate that the children again associated the chance of Jefferson visiting each friend to the number of gifts. Considering the TRSR, we may consider that the children performed a conversion from figurative representation to mother tongue, that is, when observing the 3-D pictogram, they verbalized that the one who had the best chance of being visited by Jefferson. In this case it was 
Babi. After that, the children sat on the floor and, in a conversation group, the following dialogue was established between the researcher and the children.

Researcher: Guys, before we finish our game, I'd like to ask you: Why did we visit Babi more in the draw?

$D 5_{1}$ : $\quad$ Because in that game we received two Babis and had to take two paths to get to her house.

Researcher: Precisely! There are two paths to get to Babi's house (Moving on the board and demonstrating both paths.)

Researcher: How many paths are there to get to Pelé's house?

All: $\quad$ One!

Researcher: Look, there's only one path, east, east (performing the movement on the board.)

Researcher: And to get to Duda's house?

All: $\quad$ One!

Researcher: North, north, you see? Only one path (performing the movement on the board.)

Researcher: That's why Babi has a better chance of being visited, because there are two paths to get to her house and only one path to get to Pelé's and Duda's houses. Wow, congratulations.

We consider this moment of socialization important, because the children confirmed what they had said before and after the experiment, that is, that Babi had better chances of being visited by Jefferson, but they were led to reflect on the association between the chances of each friend and the number of paths, and not only by the number of gifts received by them. Way (2003), Tatsis et al. (2008), HodnikČadež and Škrbec (2011) and Vita et al. (2016) also found similar results, because in their studies, from collective oral discussions (children did not master writing), children gradually explored probabilistic concepts with each task, reflecting, in particular, on the most and least likely events, based on comparisons and associations with the results of previous tasks.

Lastly, by analyzing our results considering the TRSR, we found that the children were able to perform a treatment in the figurative representation, as they associated the chances of being visited of each friend to the number of possible paths, obtained in the previous task. Consequently, there was also conversion from figurative representation to mother tongue, and if they had mastery of writing, they would probably also make the conversion to numerical symbolic representation.

\section{FINAL CONSIDERATIONS}

In a global analysis, we found that there was a growing appropriation, by the children, of the SE PAJ pieces and tasks that comprise the TM. This conclusion was confirmed, for example, in the children's performance during the execution and discussion of the fifth task: quick movements on the board associated with the sound of the bell, correct correspondence between the friend visited and the gift to be received, and confirmation that Babi had a better chance of being visited by Jefferson because there were two possible paths to get to her house.

Regarding the analyses from the perspective of the TRSR, we observed that representations in the mother tongue and figurative representations were used by the children, emphasizing that the use of figurative representation was the most recurrent. These included gestures, trees of possibilities, and pictograms. This may have occurred because the children had not mastered how to read and write yet. As a concequence they used other signs, in this case the figurative signs, to externalize their thoughts. However, as highlighted at various points during the analysis, it is possible that they may also make use of numerical symbolic representation, if they could express themselves in that manner.

Given the results, we then consider that the TM actually presents potential to mobilize - in the conduct of the tasks associated with the use of the pieces-the different registers of semiotic representations simultaneously, promoting treatments and conversions. Thus enabling students to apprehend the probabilistic concepts, especially in this article, the concept of chance, in order to foster the use of different registers. As a result, contributing to the development of reasoning, analysis, and visualization of the concepts, and ultimately to the students' probabilistic literacy.

As final considerations, we point out, once again, that to approach the concept of chance in our research, we followed the guidelines of international studies in statistics education, especially those mentioned in the introduction, with emphasis on Watson's (2006) definition of the concept of chance and recommendations for addressing probalistic situations with children. From these perspectives, we presented the children with tasks, with an initial context, stimulating the discussion of the situations 
orally, and finally, establishing a collective discussion, always showing a more intuitive approach to the concept of chance. Despite finding some similarities between our results and these studies, the international literature lacks studies like ours, where the concept of chance, the use of concrete material, and the Theory of Registers of Semiotic Representations (TRSR) with children of early childhood education work together.

Observing the surveys done by Colombo et al. (2008), Brandt and Moretti (2014) and Pontes et al. (2017), from 1999 to 2015 in Brazil only two dissertations involving TRSR and probability were published, one with high school students and the other in higher education. Besides these surveys, we are aware that, in this period, two more dissertations were published (high school and higher education). This paper goes some way to addressing this dirth of research in the Brazilian context, particulary in ealry childhood education. We emphasize that our research project may be innovative, both in Latin America and worldwide, and we hope that our results encourage other studies on the same theme, bringing contributions to a more global discussion about the potential of approaching the concept of chance in early childhood education under the TRSR perspective.

\section{REFERENCES}

Batanero, C. (2006). Razonamiento probabilístico em la vida cotidiana: Un desafio educativo. In P. Flores \& J. Lupiáñez (Eds.), Investigación em el aula de Matemáticas. Estadística y Azar. Procedding of the Sociedad de Educación Matemática Thales, Granada. http://www.ugr.es/ batanero/pages/ARTICULOS/ConferenciaThales2006.pdf

Batanero, C., \& Godino, J. (2002). Stochastics and its didactics for teachers: Edumat-teachers project. Universidad de Granada.

Bogdan, R. C., \& Biklen, S. K. (1994). Investigação qualitativa em educação: Uma introdução à teoria e aos métodos. Porto Editora.

Borovenik, M. (2018). Fundamental concepts and their key properties in probability: How to identify them and provide sustaining intuitions. In M. A. Sorto, A. White \& L. Guyot (Eds.), Looking Back, Looking Forward. Proceedings of the Tenth International Conference on Teaching Statistics (ICOTS10), July 8-13, Kyoto, Japan. https://iase-web.org/icots/10/proceedings/pdfs/ICOTS10_6E1.pdf?1531364280

Brandt, C. F., \& Moretti, M. T. (2014). O cenário da pesquisa no campo da educação matemática à Luz da Teoria dos Registros de Representação Semiótica. Perspectiva da Educação Matemática, 7(13), 22-37. https://periodicos.ufms.br/index.php/pedmat/article/view/488/361

Brasil Ministério da Educação e do Desporto \& Secretaria de Educação Fundamental. (1998). Referencial curricular nacional para a educação infantil. Volume 1, 2 e 3. MEC/SEF.

Brasil Ministério da Educação e do Desporto \& Secretaria de Educação Básica. (2017). Base Nacional Comum Curricular (BNCC): MEC/Secretaria de Educação Básica.

Brasil Ministério da Educação e do Desporto \& Secretaria de Educação Básica. (2018). Base Nacional Comum Curricular: Ensino Médio. MEC/Secretaria de Educação Básica.

Cazorla, I. M. (2006). Teaching statistics in Brazil. In A. Rossman \& B. Chance (Eds.), Working Cooperativley in Statisitcs Education. Proceedings of the 7th International Conference on Teaching Statistics (ICOTS 7), July 2-7, Salvador, Brazil.

https://iase-web.org/documents/papers/icots7/9A2_CAZO.pdf?1402524966

Colombo, J. A. A., Flores, C. R., \& Moretti, M. T. (2008). Registros de representação semiótica nas pesquisas brasileiras em Educação Matemática: Pontuando tendências. Zetetiké, 16(29), 41-72. https://periodicos.sbu.unicamp.br/ojs/index.php/zetetike/article/view/8647035/13936

Coutinho, C. Q. S. (2001). Introduction aux situations aléatoires dès le collège: de la modélisation à la simulation d'expériences de Bernoulli dans l'environnement informatique Cabri-géomètre II. Tese (Doutorado). Joseph Fourier University.

Dias, A. L. B. (2004). O ensino de probabilidade: Módulo do Projeto Gestar. Brasíl MEC.

Duval, R. (1995). Sémiosis et pensée humaine. Peter Lang.

Duval, R. (2003). Registros de representações semióticas e funcionamento cognitivo da compreensão em Matemática. In S. D. A. Machado (Org.). Aprendizagem em Matemática (pp. 11-33). Papirus. 
Duval, R. (2011). Ver e ensinar a matemática de outra forma: Entrar no mundo matemático de pensar os registros de representações semióticas. In T. M. M. Campos (Org.), PROEM, 2011. Práxis Educativa, 7(2), 603-607.

Elbehary, S. G. A. (2019). The necessity of revising primary school content of probability in Egypt to enhance students' probabilistic reasoning. In S. Budgett (Ed.), Decision Making Based on Data. Proceedings of the Satellite Conference of the International Association for Statistical Education (IASE), August 13-16, Kuala Lumpur, Malaysia. https://iaseweb.org/documents/papers/sat2019/IASE2019\%20Satellite\%20130_ELBEHARY.pdf?156966656 6

Gal, I. (2005). Towards 'probability literacy' for all citizens. In G. A. Jones (Ed.), Exploring probability in school: Challenges for teaching and learning (pp. 39-63). Springer.

HodnikČadež, T., \& Škrbec, M. (2011). Probability of pre-school and early school children. Eurasia Journal of Mathematics, Science \& Technology Education, 7(4), 263-279.

Kataoka, V. Y., Rodrigues, A., \& Oliveira, M. S. (2007). Utilização do conceito de probabilidade Geométrica com recurso didático no ensino de Estatística. Procceding of the IX Encontro Nacional de Educação Matemática, Belo Horizonte, Minas Gerais, Brasil.

Kataoka, V. Y., Vita, A. C., \& Cazorla, I. M. (2017). Proposição de sequências de ensino de Estatística $e$ de Probabilidade para a educação básica na perspectiva do Desenho Universal para Aprendizagem. Projeto de pesquisa. UESC.

Kataoka, V. Y., Vita, A. C., Cazorla, I. M. (2018). Ensino de Probabilidade no contexto da maquete tátil: Investigação sob a ótica da teoria dos registros de representações semióticas. Projeto de pesquisa. UESC.

Lopes, C. E. (2003). O conhecimento profissional dos professores e suas relações com estatística e probabilidade na educação infantil. [Doutorado em Educação, Universidade Estadual de Campinas]

Lopes, C. E. (2008). O ensino da Estatística e da Probabilidade na educação básica e a formação dos professores. Caderno Cedes, 28(74), 57-73.

Nikiforidou, Z. (2018). Probabilistic thinking and young children: Theory and pedagogy. In A. Leavy, M. Meletiou-Mavrotheris, \& E. Paparistodemou (Eds.), Statistics in early childhood and primary education (pp. 21-34). Springer.

Nikiforidou, Z., \& Pange, J. (2010). The notions of chance and probabilities in preschoolers. Early Childhood Education Journal, 38(4), 305-311.

Nishinaka, N., \& Yoshikawa, A. (2018). Classroom design to judge by statistical probability in junior high school. In M. A. Sorto, A. White \& L. Guyot (Eds.), Looking Back, Looking Forward. Proceedings of the Tenth International Conference on Teaching Statistics (ICOTS10), Kyoto, Japan. https://iase-web.org/icots/10/proceedings/pdfs/ICOTS10_2G2.pdf?1531364244

Pontes, H. M. de S., Finck, C. B., \& Nunes, A. L. R. (2017). O estado da arte da teoria dos registros de representação semiótica na educação matemática. Educação Matemática Pesquisa, 19(1), 297-325. https://revistas.pucsp.br/emp/article/view/30291/pdf

Rabardel, P. (1995). Les hommes et les tecnologies: Approche cognitive des instruments contemporains. Armand Colin.

Rao, K., \& Meo, G. (2016). Using universal design for learning to design standards-based lessons. SAGE Open, 6(4). http://dx.doi.org/10.1177/2158244016680688

Tatsis, K., Kafoussi, S., \& Skoumpourdi, C. (2008). Kindergarten children discussing the fairness of probabilistic games: The creation of a primary discursive community. Early Chilhood Education Journal, 36(3), 221-226.

Vergnaud, G. A. (1983). Multiplicative structures. In R. A. Lesh, \& M. Landau (Eds.). Acquisitions of mathematics concepts and procedures (pp. 127-174). Academic Press.

Vita, A. C., Kataoka, V. Y., Cazorla, I. M., Magina, S. M. P., Ferandes, S. H. A. A., Healy, S. V., Ambrosio, P., Penteado, M. G., Silveira, E. S., \& Silva, A. C. P. da. (2012). Análise Instrumental de uma Maquete Tátil para a Aprendizagem de Probabilidade por Alunos Cegos. Tese de Doutorado em Educação Matemática. Pontifícia Universidade Católica de São Paulo.

Vita et al. (2016). Aplicação de tarefas de Probabilidade no contexto da maquete tátil a alunos da educação básica: Investigações à luz de teorias da educação matemática. Projeto de pesquisa. UESC. 
Vygotsky, L. S. (1988). A formação social da mente. In M. Cole, V. John-Steiner \& S. Scribner (Orgs). J. Cipolla Neto, L. S. M. Barreto \& S. C. Afeche (Trans.). Livraria Martins Fontes Editora.

Way, J. A. (2003). The development of children's notions of probability. [Doctoral dissertation, University of Western Sydney]

Walichinski, D., \& Santos Junior, G. (2013). Educação estatística: Objetivos, perspectivas e dificuldades. Imagens da Educação, 3(3), 31-37.

Watson, J. (2006). Statistical literacy at school: Growth and goals. Laurence Erlbaum.

VERÔNICA YUMI KATAOKA

Universidade Estadual de Santa Cruz,

Campus Soane Nazaré de Andrade,

Rodovia Jorge Amado, km 16, Bairro Salobrinho,

CEP 45662-900. Ilhéus-Bahia 